\title{
Some Properties of Prosodic Phrasing in Thompson Salish
}

\author{
Karsten A. Koch \\ Zentrum für Allgemeine Sprachwissenschaft, Berlin
}

In Nłe?kepmxcin, consonant-heavy inventories, lengthy obstruent clusters and widespread glottalization can make potential F0 cues to prosodic phrase boundaries (e.g. boundary tones or declination reset) difficult to observe phonetically. In this paper, I explore a test that exploits one behaviour of phrasefinal consonant clusters to test for prosodic phrasing in Nłe?kepmxcin clauses. Final $/ \mathrm{t} /$ of the $1 \mathrm{pl}$ marker $k t$ is aspirated when phrase-final, but not phraseinternally. Use of this test suggests that Thompson Salish speakers parse verbs, arguments and adjuncts into separate phonological phrases. However, complex verbal predicates and complex noun phrases are parsed as single phonological phrases. Implications are discussed, especially in regards to findings that (absence of) pitch accent is not employed to signal the informational categories of Focus and Givenness, even though Nłe?kepmxcin is a stress language.

\section{Introduction}

The Salish languages of the Pacific Northwest of North America are well known for their rich consonantal inventories, widespread glottalization, and lengthy obstruent clusters (e.g. Kinkade 1992, Bagemihl 1991, Shaw 2002). Because obstruents are well known to affect the pitch of adjacent resonants (e.g. Brown and Thompson 2006 on Upriver Halkomelem Salish), it can be very difficult to measure potential F0 cues to prosodic phrasing, such as boundary tones and declination reset, in Salish languages. In this paper, I explore an alternative phonetic cue to prosodic phrasing in Nłe?kepmxcin (Thompson River Salish), one that in fact takes advantage of the widespread distribution of obstruents. Specifically, I will show that the final /t/ of the $1^{\text {st }}$ person plural marker $k t$ is aspirated in phrase-final position, but not phrase-internally.

Application of this test in different positions in the Thompson Salish clause will lead to the following conclusions about prosodic phrasing: (i) verb, arguments and adjuncts are parsed into separate prosodic phrases (unlike for example, English, where verb and object are often parsed into a single prosodic 
phrase), and (ii) complex predicates (auxiliary-verb constructions) and complex Noun Phrases are parsed into single prosodic phrases. Results are discussed in light of evidence that Salish languages, despite being stress languages, do not mark informational prominence through pitch accent.

In this paper, I will be referring to phonological phrases (p-phrase) and intonational phrases (i-phrases) in the prosodic hierarchy of Nespor and Vogel (1986, also Hayes 1989). I will be primarily interested in determining what syntactic constituents map into phonological phrases, currently a well-studied issue in the interface of syntax and phonology (e.g. Truckenbrodt 1995, Legate 2003, Selkirk and Kratzer 2007, An 2007, Kandybowicz 2009, etc.).

\section{Background}

Nłe?kepmxcin is one of 23 Salish languages (Thompson and Thompson 1992, 1996; Kinkade 1992, Czaykowska-Higgins and Kinkade 1998, Kroeber 1999, for some general overviews of Salishan). It is spoken in the southwest of British Columbia, and is severely endangered, with no more than a few hundred elderly speakers remaining. The phonemic inventory is given in Table 1 .

Table 1: Phonemic inventory (adapted from Thompson and Thompson 1992)

\begin{tabular}{|c|c|c|c|c|c|c|c|}
\hline CONSONANTS & labial & alveolar & $\begin{array}{l}\text { alveo- } \\
\text { palatal }\end{array}$ & velar & uvular & pharyngeal & glottal \\
\hline Stops & $\mathrm{p}$ & $\mathrm{t}$ & & $\mathrm{k} \mathrm{k}^{\mathrm{w}}$ & $\mathrm{q} \mathrm{q}^{\mathrm{w}}$ & & $?$ \\
\hline Ejectives & $\dot{\mathrm{p}}$ & $\mathrm{t}^{\prime}$ & & $\mathrm{k} \mathrm{k}^{\mathrm{w}}$ & $\dot{\mathrm{q}} \dot{\mathrm{q}}^{\mathrm{w}}$ & & \\
\hline Lateral Eject. & & $\dot{x}$ & & & & & \\
\hline Nasal & $\mathrm{m}$ & $\mathrm{n}$ & & & & & \\
\hline Glottalized & $\dot{\mathrm{m}}$ & $\dot{\mathrm{n}}$ & & & & & \\
\hline Affricates & & c $[\mathrm{ts}]$ & $\mathrm{c}[\mathrm{t} \mathrm{f}]$ & & & & \\
\hline Ejective & & $\mathrm{c}\left[\mathrm{ts}^{\prime}\right]$ & & & & & \\
\hline Fricatives & & $\mathrm{s}[\mathrm{s}]$ & $\mathrm{s}[\mathrm{s}]$ & $\mathrm{x} \mathrm{x}^{\mathrm{w}}$ & $x x^{w}$ & & $\mathrm{~h}$ \\
\hline Lateral & & 1 & & & & & \\
\hline Approximant & (w) & $\mathrm{Z}$ & $y[j]$ & W & & $\oint \Upsilon^{\mathrm{w}}$ & \\
\hline Lateral & & 1 & & & & & \\
\hline Glottalized & $(\mathrm{w})$ & $\dot{Z}$ & ý & $\stackrel{\mathrm{W}}{ }$ & & $\mathrm{S}^{\prime} \mathrm{\rho}^{\prime \mathrm{w}}$ & \\
\hline Glott. Lateral & & 1 ' & & & & & \\
\hline
\end{tabular}

\begin{tabular}{rccccc} 
Vowels & & front & & central & back \\
\hline high & $\mathrm{i}$ & $\mathrm{i}$ & & & $\mathrm{u}$ \\
mid & $\mathrm{e}$ & & ə & ค & $\mathrm{o}$ \\
low & & & $\mathrm{a}$ & \\
\hline
\end{tabular}


Like all Salish languages, Thompson Salish is predicate-initial. The typical order is Verb-Subject-Object-Adjunct, though post-predicative verb order is in practice quite flexible. Predicates are obligatorily inflected for transitivity and subject/object agreement markers (see Thompson and Thompson 1992). Second position clitics (2CL) follow the first prosodic word. DPs are obligatorily marked with determiners. A typical sentence is shown in (1). ${ }^{1}$
(1)
Verb
2CL Subject
kən-t-Ø-és =xe?
$\mathrm{e}=$ skíxze?-kt
help-TR-3O-3S $=$ DEM
DET=mother-our
Object
$\mathrm{e}=$ sínci?-kt.
DET=brother-our
'Our mother helped our brother.'

There has been little previous research on properties of prosodic phrasing in the language: the grammar mentions a few general pitch cues (Thompson and Thompson 1992:24), while Egesdal (1984) details some general rhythmic properties of narratives, again only impressionistically. Koch (2008) is the first work to examine potential phonetic cues to prosodic phrasing, and the current paper follows up on this work.

Looking across the Salish language family more generally, there again has been much work on prosodic categories below the level of phrases (e.g. Shaw 2002, Czaykowska-Higgins 1993, 1998, Thompson and Thompson 1992, etc.), but comparatively little at the phrasal level. A notable exception, Beck (1996, 1999) identifies the following indicators of p-phrase status in Lushootseed Salish (see also Beck and Bennett 2007):

(2) Characteristics of phonological phrases in Lushootseed Salish (Beck 1999)
a. set off by 50-100 ms pause in careful speech
b. lack phonological interaction (i.e. assimilation, etc.) across p-phrase boundaries
c. contain a single phonological word with an amplitude peak plus clitics and affixes

In addition, Beck (1999) notes that intonational phrases in Lushootseed are characterized by a steady fall in F0, with a declination reset at the start of each i-phrase. In Okanagan Salish, prosodic boundaries are also marked by pauses, F0 fall, and reset or partial reset of declination across phrasal boundaries (Barthmaier 2004). Finally, recent work by Caldecott (2009) shows that

\footnotetext{
${ }^{1}$ See the appendix for a key to orthography and glosses.
} 
prosodic phrases are right-headed in St'át'imcets Salish; Koch (2008) finds that Thompson Salish, too, has rightmost nuclear stress and right-headed phonological-phrases.

In the remainder of this paper, I explore a (lack of) assimilation effect in the spirit of (2b): phrase-final aspiration of $/ \mathrm{t} /$ in the $1^{\text {st }}$ person plural marker $k t$.

\section{Phrase-final aspiration of $k t$ : A test to distinguish p-phrase boundaries}

The enclitic or suffix $k t$ indicates $1^{\text {st }}$ person plural $(1 \mathrm{pl})$ subjects in both indicative and nominalized intransitive clauses, as well as $1^{\text {st }}$ person plural possessors. In this section, I present phonetic evidence that the $/ t /$ of the $1^{\text {st }}$ person plural marker $k t$ is aspirated phrase-finally, but not phrase internally. I start by showing this in simple verb phrases (3.1). Next, I show that the aspiration test indicates that, verb, subject and object are phrased separately, as are verbs and adjuncts (3.2). Finally, I show that the language does not simply parse each prosodic word (PWd) into a phrase (contra Beck 1999, who suggests this may happen in Lushootseed Salish - 2c; see also Hellmuth 2006 who argues that in Cairene Arabic each PWd is pitch accented, which is not the case here). First, I show that complex verbal predicates consisting of one or more auxiliaries and a verb are parsed as one p-phrase (3.3). I will close by showing that complex Noun Phrases consisting of an NP and a modifier are similarly parsed as a single p-phrase (3.4).

All data in this paper come from my own data corpus collected during

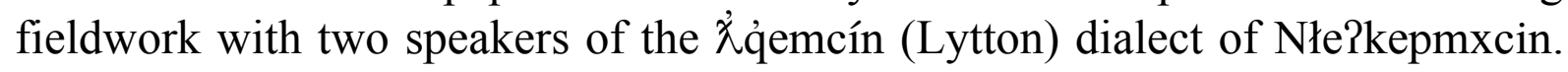
Speakers were recorded on separate channels using a digital audio recorder and individual microphones. The utterances examined in this paper all stem from a single breath group (single intonational phrase in the prosodic hierarchy).

\subsection{Aspiration of $k t$ in simple clauses: restriction to phrase-final position}

In (3a), the $1 \mathrm{pl}$ indicative enclitic $k t$ occurs sentence-finally, while in (3b) it is followed by the evidential marker $n u k^{w}$.
a. téyt $=\mathrm{kt}$.
b. téyt $=\mathrm{kt}=\mathrm{nke}$.
hungry $=1$ PL.INCL
hungry $=1 \mathrm{PL} . \mathrm{INCL}=\mathrm{EVID}$
'We are hungry.'
'We are hungry.'

When the $1 \mathrm{pl}$ marker $k t$ occurs in a clearly phrase-final position - the end of a sentence - it is strongly aspirated (in itself a noteworthy property of Thompson Salish). This is shown below in the sentence téyt $k t$ 'We are hungry.' In fact, all 
three of the final stops are aspirated; for our purposes we are concerned with phrase-final /t/ of the $1 \mathrm{pl} k t$ marker.

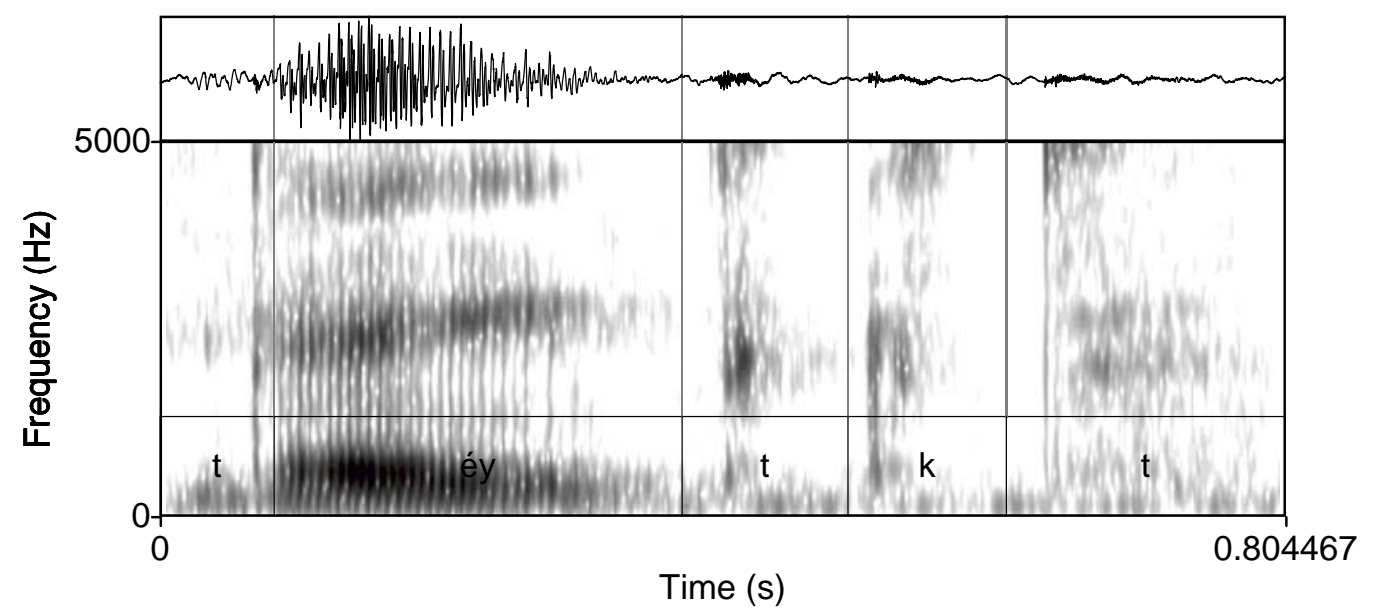

Figure 1: Final aspiration of /t/ in $k t(3 a)$

When the $1 \mathrm{pl}$ marker $k t$ is followed by another enclitic, the evidential nke, the final $/ \mathrm{t} /$ is no longer aspirated. I take this to show that the clitic string $=k t=n k e$ has undergone phrase-internal assimilation. Note that within the $1 \mathrm{pl} \mathrm{clitic} k t$, the $/ \mathrm{k} /$ is still strongly aspirated (as it is in all the examples we will see). Thus, the final aspiration of $k t$ really is a boundary effect.

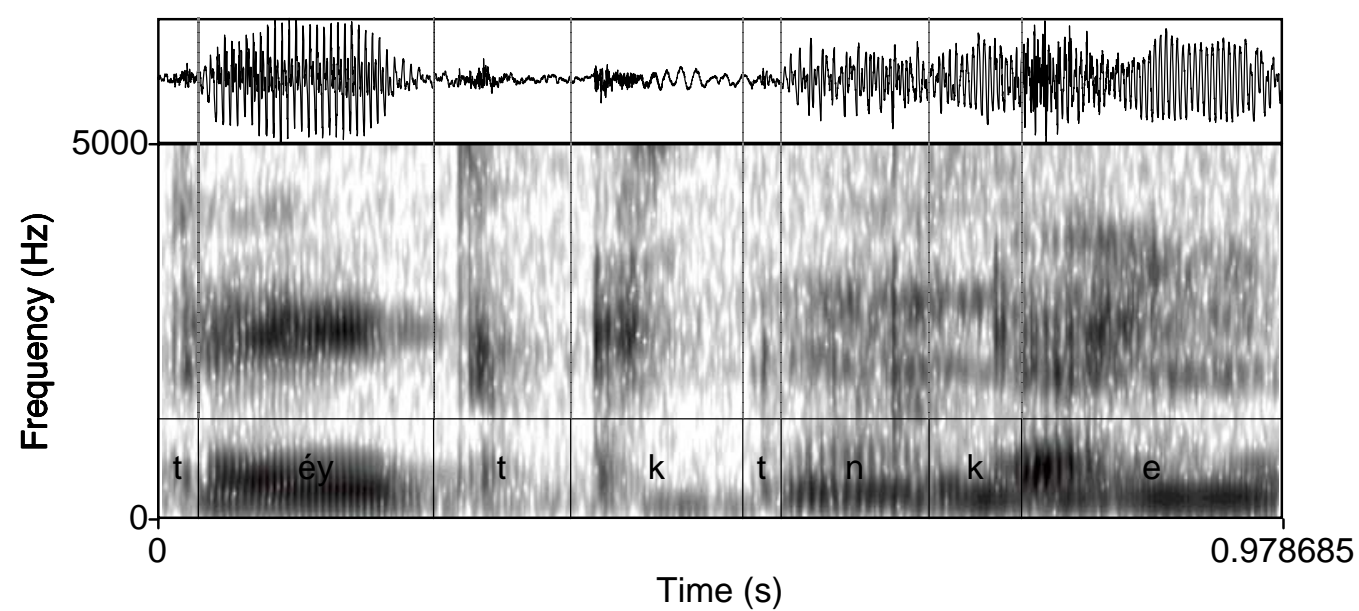

Figure 2: No aspiration of /t/ in $k t$ when phrase-internal (3b) 


\subsection{Aspiration of $k t$ between constituents of more complex clauses}

In this section, I use the $k t$ aspiration test to probe for prosodic phrase boundaries between major constituents within a clause. Following Nespor and Vogel (1986), the entire clause is parsed into a single i-phrase. Thus, this test will probe for p-phrase boundaries (though nothing hinges on the model used).

In (4), both subject and object are suffixed with $k t$ to mark $1 \mathrm{pl}$ possession.

$$
\begin{array}{llll}
\text { kən-t-Ø-és } & =x e 2 & \mathrm{e}=\text { skíxze2-kt } & \mathrm{e}=\text { sínci?-kt. } \\
\text { help-TR-3O-3s } & =\text { DEM } & \text { DET=mother-our } & \text { DET=brother-our }
\end{array}
$$

'Our mother helped our brother.'

As expected, the sentence-final [t] is aspirated (figure 3). In addition, however, we see that the $1 \mathrm{pl}$ marker $k t$ after the subject skixze? 'mother' is also aspirated. This indicates a phrase boundary between subject and object. Figure 3 shows just the two final Noun Phrases skixze?-kt e sinci?-kt, and the two occurrences of $k t$ are marked. At the same time, we see that the sentence-final aspiration is longer, as we would expect if the entire clause is parsed in a right-headed intonational phrase with increased final lengthening on the dominant constituent.

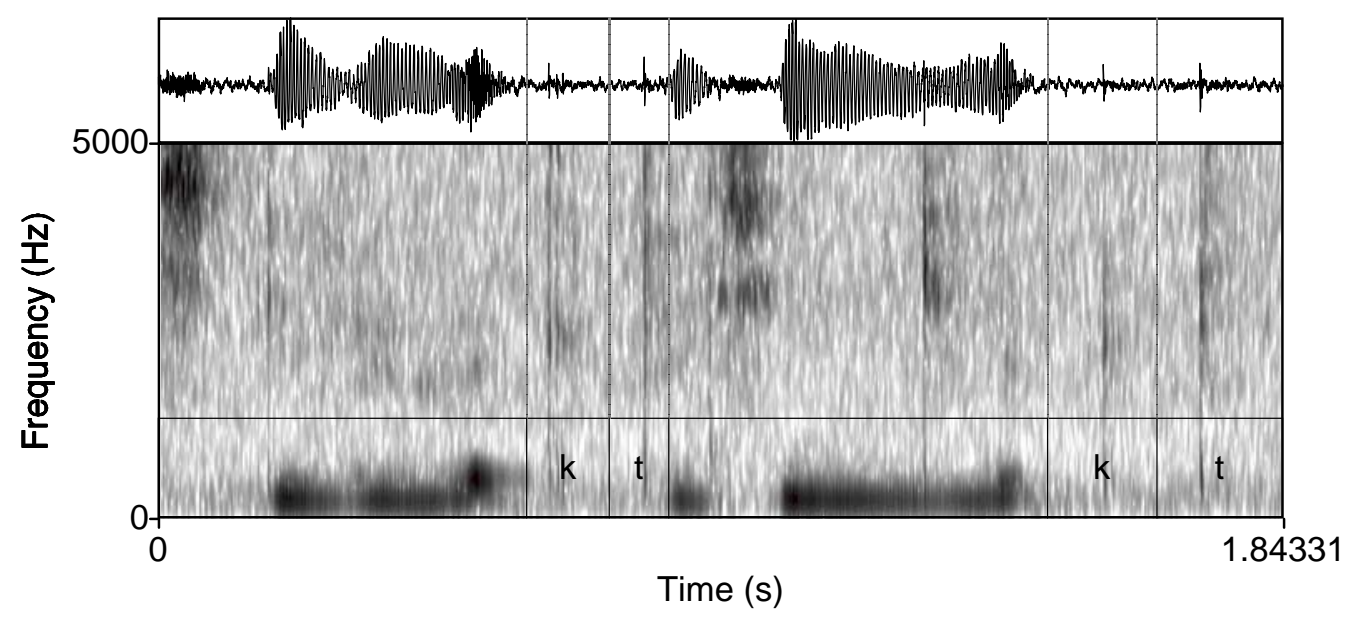

Figure 3: Aspiration of $/ \mathrm{t} /$ in $k t$ between subject and object of (4)

In the next example, the verb $n \Upsilon^{w}$ oy $t^{\prime}$ 'sleep,' bearing the $1 \mathrm{pl}$ possessive subject enclitic $k t$, is followed by an adjunct, the temporal adverb 1 sitist 'last night.'

$$
\begin{array}{lll}
\text { yé } \quad \mathrm{e}=\mathrm{s}=\mathrm{n}-\mathrm{S}^{\mathrm{w}} \text { óyt }=\mathrm{kt} & \mathrm{l}=\text { sítist. } \\
\text { good } \quad \mathrm{COMP}=\mathrm{NOM}=\mathrm{LOC}-\mathrm{sleep}=1 \mathrm{PL} . \text { POCL } & \mathrm{DET}=\text { night } \\
\text { 'We slept really good last night.' } &
\end{array}
$$


In Figure 4, we see aspiration of the $/ \mathrm{t} /$ in $k t$ before the fricatives [ $\left.1 \int\right]$ of the temporal adjunct phrase. The $k t$ aspiration test shows that verbs and adjuncts are parsed into separate prosodic phrases.

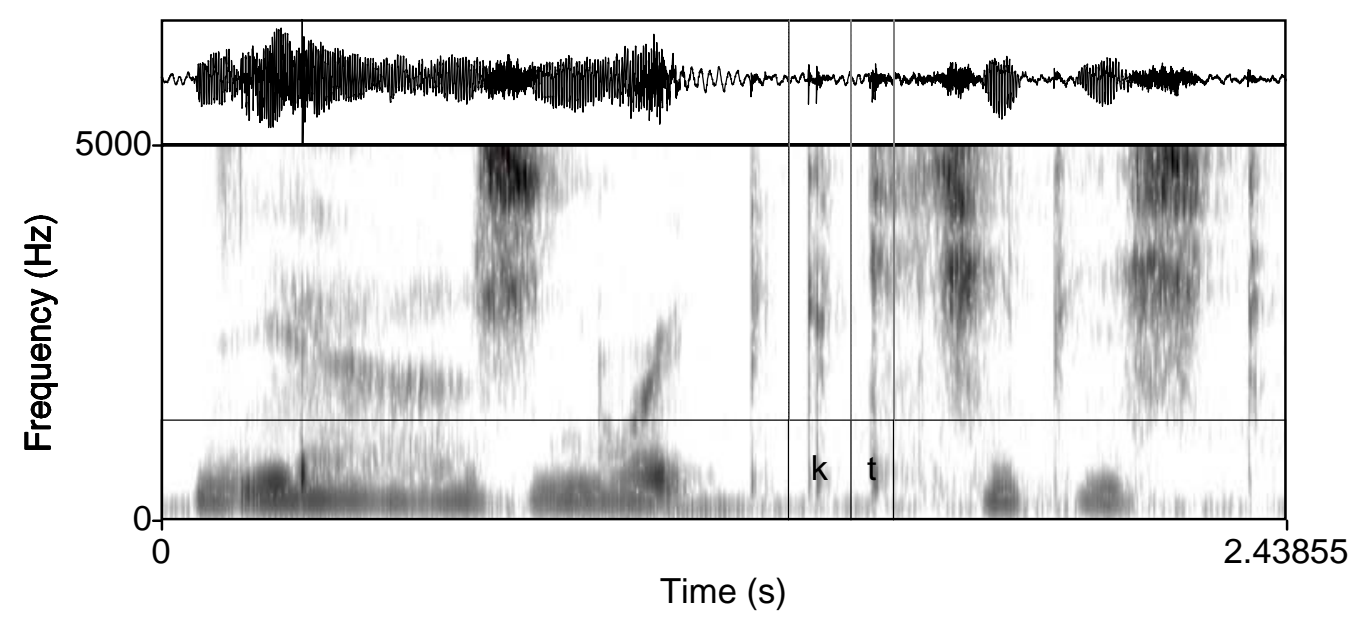

Figure 4: Aspiration of $/ \mathrm{t} /$ in $k t$ between verb and temporal adjunct

Finally, in (6), the verb pent 'return' bears the $1 \mathrm{pl}$ possessive subject enclitic $k t$, and is followed by the Preposition Phrase $w$ e șkul 'to school.'

(6)
Pe $\quad \mathrm{s}=\dot{\mathrm{pénht}}=\mathrm{kt}$
$\mathrm{w}=\mathrm{e}=$ skúl.
and $\quad \mathrm{NOM}=$ return $=1 \mathrm{PL} . \mathrm{POCL} \quad$ to $=\mathrm{DET}=$ school
'And we went back to school.'

In figure 5 we see aspiration of the final $[\mathrm{t}]$ of $k t$, suggesting that the verb is parsed into a separate phonological phrase from the PP adjunct. 


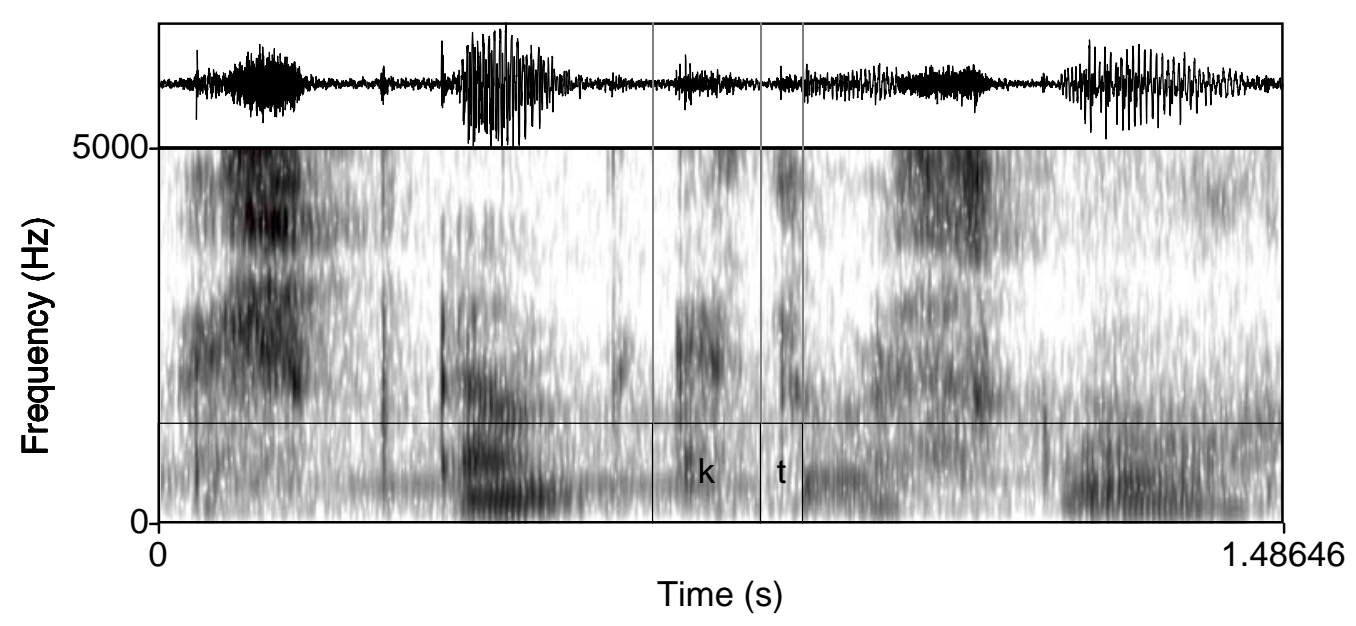

Figure 5: Aspiration of $/ \mathrm{t} /$ in $k t$ between verb and PP adjunct

In this section, I showed that the $k t$ aspiration test suggests that verbs, arguments and adjuncts are parsed into separate phonological phrases.

\subsection{Complex verbal predicates are parsed as one p-phrase}

The verb may co-occur with one or more auxiliaries at the left edge of the Thompson Salish clause. When this happens, the first auxiliary attracts the second position clitics. This shows us that auxiliaries count as prosodic words. In the previous section, all examples were consistent with a phonological system in which each prosodic word is parsed into its own p-phrase, bearing its own pitch accent (see Beck 1999, 2c, on Lushootseed Salish, Hellmuth 2006 on Cairene Arabic). In this section, I show that this cannot be right for Nłe?kepmxcin, since auxiliaries and verbs are parsed into a single prosodic unit, by the $k t$ aspiration test, even though both count as prosodic words.

In (7), the $1 \mathrm{pl}$ subject marker $k t$ follows the future auxiliary $x^{w} l y$, and precedes a second auxiliary nes and the verb tewcnme 'shop for groceries.'

$$
\begin{aligned}
& \mathrm{X}^{\mathrm{w}} \mathrm{úỷ}=\mathrm{kt} \quad \text { nés téw-cn-me. } \\
& \text { FUT=1PL.INCL go buy-mouth-INTRANS } \\
& \text { 'We're going to go grocery shopping.' }
\end{aligned}
$$

Figure 6 illustrates that the [t] of $k t$ is completely unaspirated, assimilating with the following [n]. By hypothesis, $k t$ is not followed by a phrasal boundary. 


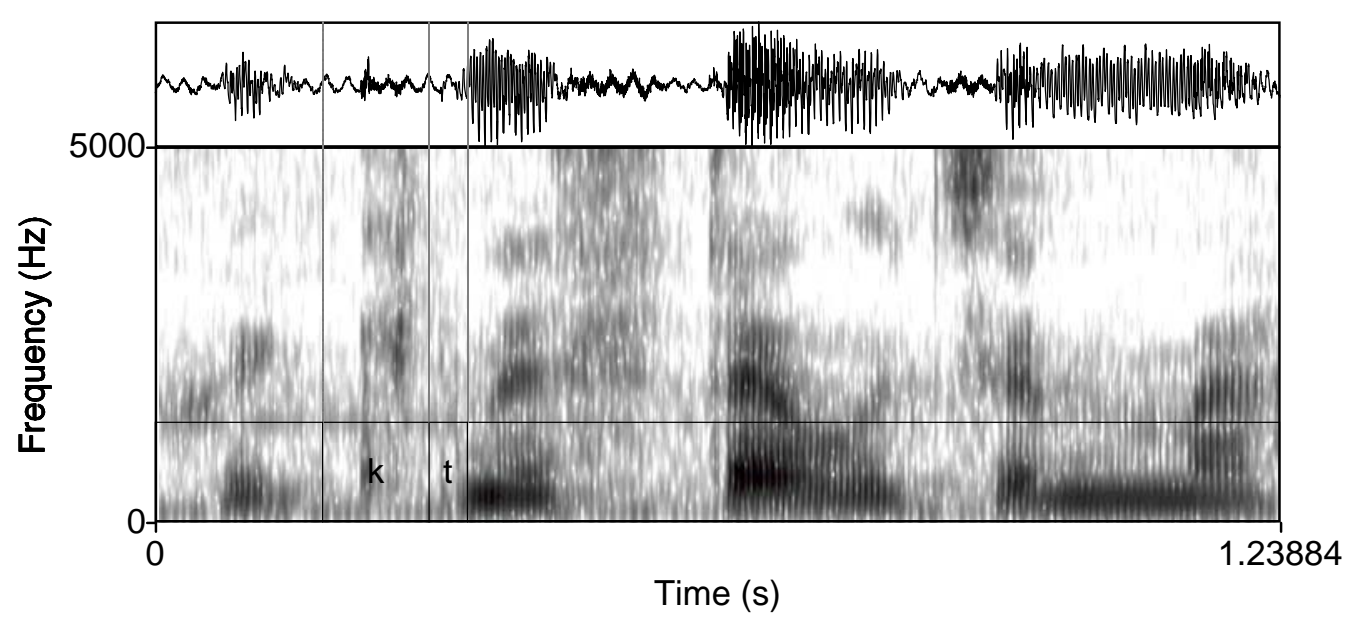

Figure 6: Non-aspiration of $/ \mathrm{t} /$ in $k t$ within verbal complex in (7)

Another case is shown in (8) and figure 7. The imperfective auxiliary w?ex carries the $1 \mathrm{pl}$ possessive enclitic $k t$, and is followed by the verb tans 'dance.' Figure 7 shows that there is no release of the /t/ of $k t$ at all, which has instead assimilated with the onset [t] of the verb tans.

(8)

$$
\begin{array}{lll}
\text { Pe } & \mathrm{s}=\mathrm{w} \text { ?é }=\mathrm{kt} & \text { táns. } \\
\text { and } & \mathrm{NOM}=\mathrm{IMPF}=1 \mathrm{PL} . \text { PoCL } & \text { dance }
\end{array}
$$

'And so we danced.'

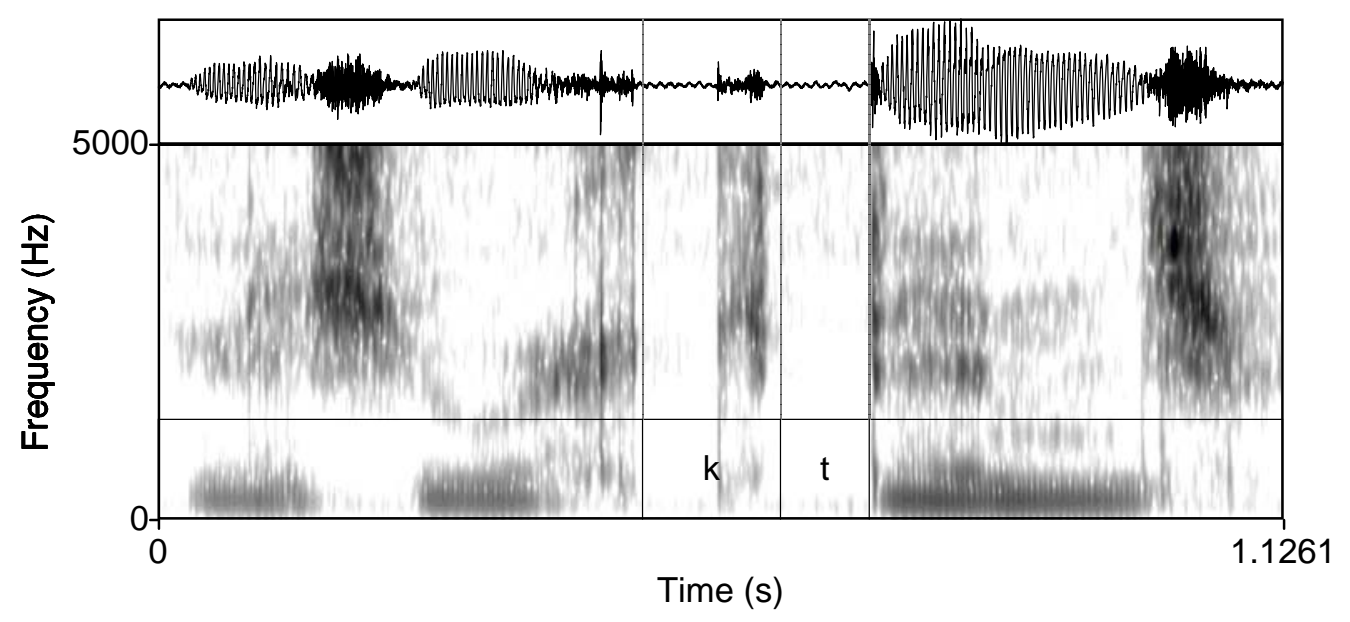

Figure 7: Non-aspiration of $/ \mathrm{t} /$ in $k t$ within verbal complex in (8) 


\subsection{Complex Noun Phrases are parsed as one p-phrase}

In the last section, I showed that the $k t$ aspiration test indicates that more than one word can be parsed into a single phonological phrase: auxiliaries and verbs. Now I show that the $k t$ aspiration test gives the same result for Noun Phrases consisting of nouns and modifiers.

In (9), 'our son' is expressed as the noun $s k^{W} u z e$ ? 'offspring' modified by sqayx ${ }^{W}$ 'man' (or 'male'). The $1 \mathrm{pl}$ possessor $k t$ intervenes. Figure 8 shows that the final $[\mathrm{t}]$ is not aspirated, again assimilating with the onset [t] of the 'link' particle te (this marks predicate modification between nouns and modifiers).

$$
\begin{aligned}
& \text { e }=\text { sk }^{\mathrm{w}} \text { úze?-kt } \quad \text { te }=\mathrm{sqá}^{\mathrm{y} \mathrm{w}^{\mathrm{w}}} \\
& \text { DET=offspring-1PL.POSS } \quad \text { LINK=man } \\
& \text { 'our son' (more literally 'our male offspring') }
\end{aligned}
$$

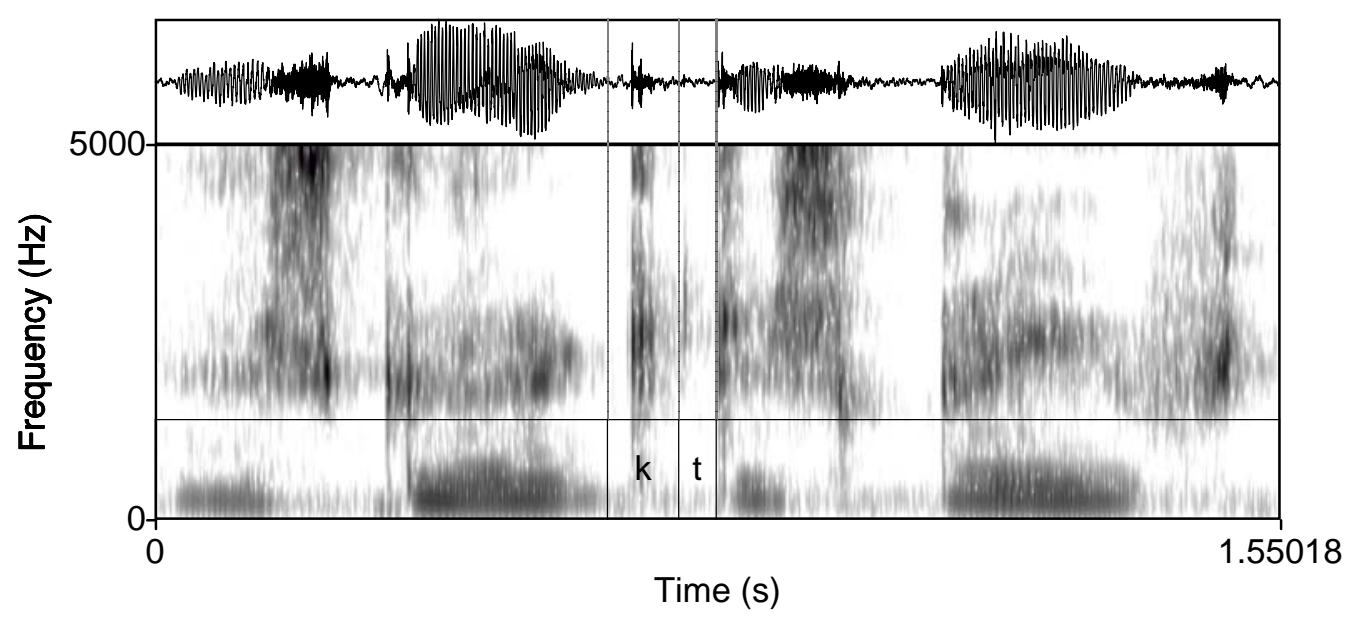

Figure 8: Non-aspiration of /t/ in $k t$ within the complex Noun Phrase in (9)

The noun smiyc 'meat' is modified by a head-initial relative clause $s k^{W} u k^{W} k t$ 'that we cooked' in (10). Like in the previous example, the final [t] of $k t$ is not aspirated, again assimilating with the onset [t] of the link particle $t e$.

$\ldots \mathrm{e}=\mathrm{s}=\mathrm{k}^{\mathrm{w}} \mathrm{ú}^{\mathrm{w}}=\mathrm{kt}$

te = smíyc.

... $\mathrm{DET}=\mathrm{NOM}=\mathrm{cook}=1 \mathrm{PL} . \mathrm{POCL}$

LINK $=$ meat

'... the meat that we cooked.' 


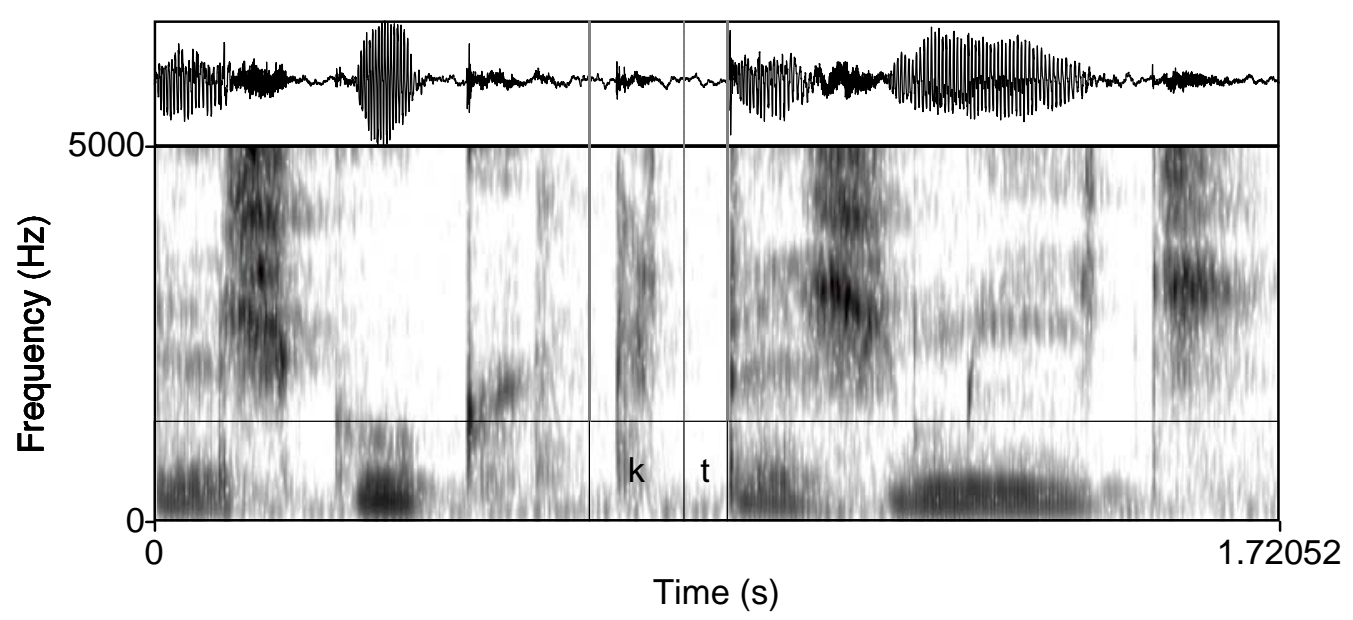

Figure 9: Non-aspiration of /t/ in $k t$ within the complex Noun Phrase in (10)

In the final example shown here, the noun 'cat' in (11a) bears the $1 \mathrm{pl}$ possessive suffix $k t$, and is followed by the modifier nmimt 'our [emphatic].' The /t/ of $k t$ is not aspirated, assimilating with the following [n]. Emphatic modifiers count as Prosodic Words, since when clefted, they attract second position clitics like any other Prosodic Word (shown for the 1sg emphatic ncewe? in 11b; see Koch 2008 for further examples). Thus, this is another case where two Prosodic Words are parsed into one larger prosodic unit, the phonological phrase.
(11)
a. $\mathrm{e}=$ púṣ-kt
nmímł
DET=cat-1PL.POSS 1PL.EMPHATIC
'our cat'
b. ncéwe? $=$ us $=$ mel
$\mathrm{k}=$ ?émic-t- $\varnothing$-mus
e = pús.
$1 \mathrm{SG} . \mathrm{EMPH}=3 \mathrm{CNCL}=$ indeed $\mathrm{COMP}=$ feed-TRANS-3O-SUBJ.GAP $\quad$ DET $=$ cat 'Let it be me that feeds the cat.' 


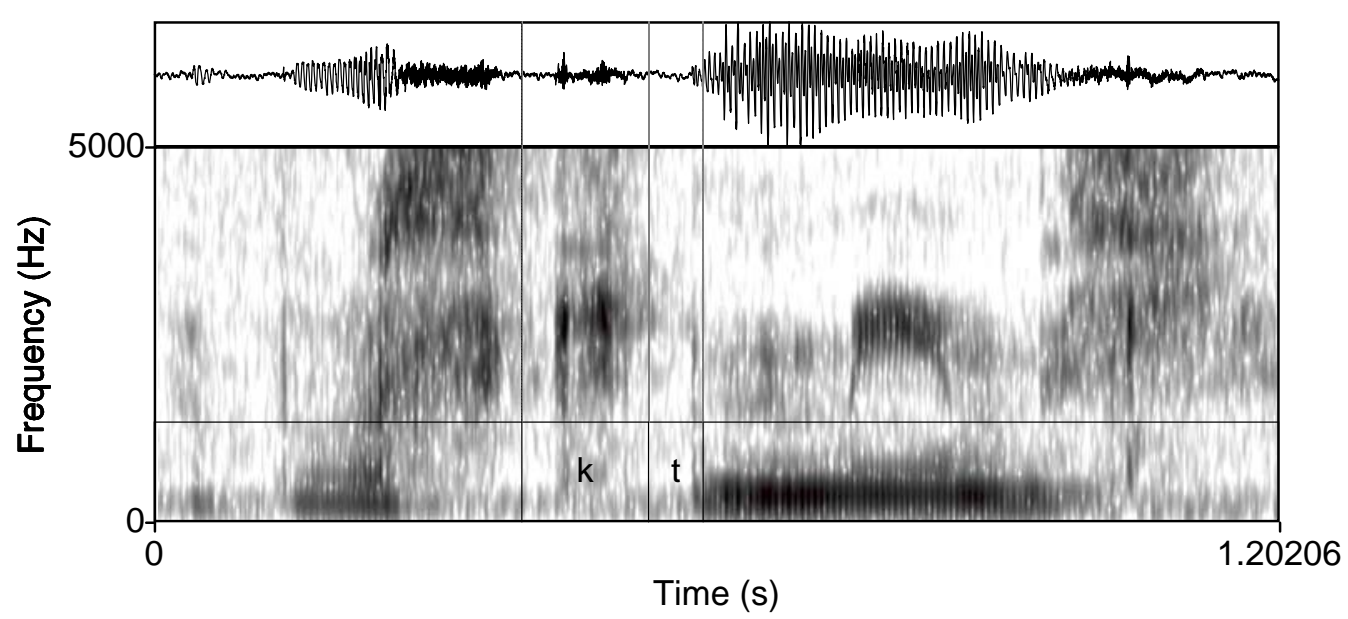

Figure 10: Non-aspiration of /t/ in $k t$ within the complex Noun Phrase in (11a)

In this section, I showed that the $k t$ aspiration test suggested that complex noun phrases are parsed as single phonological phrases.

\section{$4 \quad$ Implications}

The $k t$ aspiration test probes for phrasal boundaries within the Thompson Salish clause. In section 3, the results of the test suggest that syntactic categories are phonologically phrased in the following ways.

First, verbs and arguments are parsed into separate phonological phrases. Cross-linguistically, this is not uncommon. Beck (1999) and Barthmaier (2004) make similar claims for Lushootseed Salish and Okanagan Salish, respectively. Outside the Salish language family, Hayes and Lahiri (1991, on Bengali), Schafer and Jun (2002, on Korean), and Nespor and Sandler (1999, on Israeli Sign Language), also argue for parsing of verb and arguments into individual p-phrases (see also Ishihara 2007: 147-148, ex. 17b, for such parses of some Japanese sentences). This parsing is not typical of English, where verb and object are typically parsed into one phonological phrase, while the subject is realized in a separate p-phrase (Chomsky 1971, Jackendoff 1972, Gussenhoven 1983, Selkirk 1995, Kahnemuyipour 2004, Selkirk and Kratzer 2007). It is possible that the parsing pattern observed in Thompson Salish is correlated with a surface word order of Verb-Subject-Object (VSO), where the subject intervenes between verb and object, though this is a matter for further typological research. 
Secondly, complex predicates (auxiliaries plus verb) and complex Noun Phrases (noun plus modifier) are parsed into a single phonological phrase. This is significant because it suggests that the language does not employ a strategy where each prosodic word is pitch accented and parsed into a phonological phrase independently of its greater syntactic structure. Rather, an intermediate category, the phonological phrase, exists between the word and i-phrase levels. This category maps onto syntactic categories (DP, and the extended VP), consistent with the idea that syntactic and phonological categories interface at the level of the p-phrase (e.g. Truckenbrodt 1995, 1999, Selkirk and Kratzer 2007 , and many others).

XP-to-P Mapping Condition (Truckenbrodt 1999:221)

Mapping constraints relate [syntactic] XPs to phonological phrases, but do not relate XPs to other prosodic entities.

Phonological phrases are right-headed (Koch 2008; Caldecott 2009 on St'át'imcets Salish), and in stress languages, this is the category where focus is made prosodically prominent: focused items are heads of p-phrases. Previous findings indicate that, although it is a stress language (Thompson and Thompson 1992, Egesdal 1984), speakers of Nłe?kepmxcin do not manipulate pitch accent cues to mark the informational categories of focus and givenness. That is, there are no "Stress-Focus" or "Destress-Given" effects (Koch 2008). One possible reason would have been that pitch accents are assigned at the level of the Prosodic Word (Hellmuth 2006 on Cairene Arabic), and thus there would be no opportunity for manipulating headedness at a higher level. However, the current study suggests this is not the case: the language does have p-phrases that culminate, but they are simply not exploited to mark information structure. In the terms of Selkirk and Kratzer (2007), for example, the constraints STRESSFocus and Destress-Given (e.g. Féry and Samek-Lodovici 2006) are not part of the syntax-phonology interface in the grammar of Nłe?kepmxcin, at least not in the way that they are commonly defined. This is a significant finding, given the widespread assumption that stress languages employ stress to mark focus; it may be that this is far less widespread once we stray outside the European realm (see also Rialland and Robert 2001 on Wolof, and Lindström and Remijsen 2005 on Kuot).

On the other hand, it has been observed that a general strategy for marking the focus in many (perhaps all) Salish languages is to make the focus part of the predicate (e.g. Kroeber 1997, 1999 for overviews of clefting strategies, Benner 2006 on Sencóthen, Davis 2007 on St'át'imcets, Koch 2008 on Thompson). If, as the current findings suggest, a complex predicate is a single phonological phrase, then this apparent syntactic focus-marking strategy may have a prosodic 
purpose as well: the focus is restructured into a single p-phrase - the initial p-phrase in the clause. While such a strategy has not been widely reported for stress languages, the manipulation of prosodic phrasing to mark focus is wellknown from work on many tone languages in particular (e.g. Truckenbrodt 1999, Downing 2003, Ladd 1996 more generally on the role of phrasing).

Restructuring the focus into the initial p-phrase is consistent with a strategy that makes informationally prominent categories quickly recoverable from the speech stream for listeners. This is a strategy in line with psycholinguistic work that suggests that intonational parsing happens more rapidly than syntactic parsing, and is used to identify syntactic phrasing (Kjelgaard and Speer 1999; Jun 2003, and references on p. 220; Fodor's 1998 Implicit Prosody Hypothesis on silent reading; Callan et al. 2004 on listeners internally simulating the speech act of speakers). Kjelgaard and Speer suggest that prosodic parsing is more straighforward because it is easier to identify p-phrases and i-phrases than syntactic information. P-phrases and i-phrases have only edges and heads, and are parsed directly into each other; moreover, there are only two categories to identify. Syntactic parsing is much more complex, involving the identification of many syntactic categories, movement and traces. Moreover, signal information that demarcates phrase edges and heads can be recovered not just from the acoustic signal, but also from the visual signal (eg. Vatikiotis-Bateson 1988): acoustic parameters like F0 (Yehia et al. 2002), duration (Vatikiotis-Bateson 1988, Fletcher and Bateson 1989), and amplitude (Vatikiotis-Bateson 1988, Vatikiotis-Bateson and Kelso 1993) have visual reflexes in facial and head movement. In addition, neurolinguistic processing research provides some support for the view that $\mathrm{p}$-phrase and i-phrase processing is different: evidence suggests that linguistic prosody over small domains (words or less) may be controlled by the left hemisphere; but processing of larger units (eg. p-phrases and i-phrases), appears to span both hemispheres (Baum and Pell 1999).

If the absence of stress-focus effects in Thompson Salish is not accounted for by the lack of phonological phrases, there may be other functional explanations. One possible reason is that F0 perturbations are important cues to obstruents and glottalization, and are thus not manipulated for information structure purposes. Given the widespread glottalization in the phonemic inventory (table 1), and the lengthy obstruent clusters in surface strings in the language, this seems a possible explanation worthy of further research.

Thus, the implications of the findings are widespread for evaluation of the grammar of the language, in particular the syntax-phonology interfaec and the system of focus marking. This points to the importance of finding further phonetic cues that will also help to identify prosodic phrases in Thompson Salish. 


\section{Conclusion}

In this paper, I have used a consonant-oriented test for prosodic phrasing cues in Nłe?kepmxcin (Thompson River Salish). Phrase-final aspiration of the /t/ in $k t$ (1pl) and its non-aspiration when not at a p-phrase boundary was exploited to probe the phrasing of Thompson clauses. While verbs and arguments are parsed into different p-phrases, complex predicates and complex Noun Phrases are parsed into a single p-phrase. This finding has implications for how the syntaxphonology interface operates in Salish, both for the mapping of syntactic XPs onto phonological categories, and for the mapping of information structure into phonological categories in the absence of a stress-focus effect.

\section{Acknowledgements}

I am indebted to consultants Flora Ehrhardt and Patricia McKay, without whom this research would not be possible. This research has been supported by Jacobs and Kinkade Research Grants from the Whatcom Museum Foundation, Bellingham, WA; and by NSERC, SSHRC, and DAAD research fellowships.

\section{References}

An, Duk-Ho (2007). Clauses in non-canonical positions at the syntax-phonology interface. Syntax 10(1), 38-79.

Bagemihl, Bruce (1991). Syllable structure in Bella Coola. Linguistic Inquiry 22, 589-646.

Barthmeier, Paul (2004). Intonation units in Okanagan. In Donna B. Gerdts and Lisa Matthewson, eds. Studies in Salish linguistics in honor of M. Dale Kinkade. Missoula: UMOPL 17. 30-42.

Baum, Shari R., and Marc D. Pell (1999). The neural bases of prosody: Insights from lesion studies and neuroimaging. Aphasiology 8, 581-608.

Beck, David (1996). Some notes on phonological phrasing in Lushootseed. Toronto Working Papers in Linguistics 15(2), 37-60.

(1999). Words and prosodic phrasing in Lushootseed. In T. Alan Hall \& Ursula Kleinhenz, eds. Studies on the Phonological Word. Amsterdam: Benjamins. 23-46.

, and David Bennett (2007). Extending the prosodic hierarchy: evidence from Lushootseed narrative. Northwest Journal of Linguistics 1(1), 1 - 34.

Benner, Allison (2006). The prosody of Senchóthen. Paper given at The 41st International Conference on Salish and Neighbouring Languages, University of Victoria.

Brown, Jason, and James Thompson (2006). Criteria for tonality: The case of Upriver Halkomelem. In Shannon T. Bischoff, Lynnika Butler, Peter Norquest, Daniel Siddiqi eds. MIT Working Papers on Endangered and Lesser Known Languages: Studies in Salishan. 113-126. 
Caldecott, Marion (2009). Non-exhaustive parsing: phonetic and phonological evidence from St'át'imcets. Ph.D. dissertation, University of British Columbia.

Callan, Daniel E., Jeffery A. Jones, Kevin Munhall, Christian Kroos, Akiko M. Callan, and Eric Vatikiotis-Bateson (2004). Neural processes underlying perceptual enhancement by visual speech gestures. NeuroReport 14, 2213-2218.

Chomsky, Noam (1971). Deep structure, surface structure, and semantic interpretation. In D.D.Steinberg and L.A. Jakobovits, eds. Semantics: An Interdisciplinary Reader in Philosophy, Linguistics, and Psychology. Cambridge: Cambridge University Press. 183-216.

Czaykowska-Higgins, Ewa (1993). Cyclicity and stress in Moses-Columbia Salish (Nxa'amxcín). Natural Language \& Linguistic Theory 11, 197-278.

(1998). The morphological and phonological constituent structure of words in Moses-Columbia Salish (Nxa'amxcín). In E. Czaykowska-Higgins and M.D. Kinkade, (eds.) Salish Languages and Linguistics. Berlin: Mouton de Gruyter. 153-196.

— and Descriptive Perspectives. Trends in Linguistics: Studies and Monographs 107. Berlin: Mouton de Gruyter.

Davis, Henry (2007). Prosody-focus dissociation and its consequences: The case of Salish. Paper presented November 10, 2007, Nagoya, Japan.

Downing, Laura J. (2003). Stress, tone and focus in Chichewa and Xhosa. In Rose-Juliet Anyanwu, ed. Stress and Tone: The African Experience. Franfurter Afrikanisitische Blätter 15. Köln: Rüdiger Köppe Verlag. 59-81.

Egesdal, Steven M. (1984). Stylized Characters' Speech in Thompson Salish Narrative. Ph.D. dissertation, University of Hawaii.

Féry, Caroline, and Vieri Samek-Lodovici (2006). Focus projection and prosodic prominence in nested foci. Language 82(1), 131-150.

Fletcher, Janet, and Eric Vatikiotis-Bateson (1989). The kinematics of final lengthening in French. Journal of the Acoustical Society of America 86, 114-115.

Fodor, J.D. (1998). Learning to parse. Journal of Psycholinguistic Research 27, 285-319.

Gussenhoven, Carlos (1983). Testing the reality of focus domains. Language and Speech 26, 61-80.

Hayes, Bruce (1989). The prosodic hierarchy in meter. In P. Kiparsky and G. Youmans (eds.) Phonetics and Phonology 1: Rhythm and Meter. San Diego: Academic Press. 201-260. , and Aditi Lahiri (1991). Bengali intonational phonology. Natural Language \& Linguistic Theory 9, 47-96.

Hellmuth, Sam (2006). Intonational pitch accent distribution in Egyptian Arabic. $\mathrm{PhD}$ dissertation, SOAS, University of London.

Ishihara, Shinichiro (2007). Major phrase, focus intonation, multiple spell-out. The Linguistic Review (2-3), 137-167. 
Jackendoff, Ray (1972). Semantic Interpretation in Generative Grammar. Cambridge, MA: MIT Press.

Jun, Sun-Ah (2003). Prosodic phrasing and attachment preferences. Journal of Psycholinguistic Research 32(2), 219-249.

Kahnemuyipour, Arsalan (2004). The Syntax of Sentential Stress. Ph.D. dissertation. University of Toronto.

Kandybowicz, Jason (2009). Embracing edges: syntactic and phono-syntactic edge sensitivity in Nupe. Natural Language and Linguistic Theory 27, 305-344.

Kinkade, M. Dale (1992). Salishan languages. In: International Encyclopedia of Linguistics (Bright, William, ed.). New york: Oxford University Press. 359-362.

Kjelgaard, M.M., and S.R. Speer (1999). Prosodic facilitation and interference in the resolution of temporary syntactic closure ambiguity. Journal of Memory and Language 40(2), 153-194.

Koch, Karsten. 2008. Intonation and Focus in NłePkepmxcin (Thompson River Salish). Ph.D. dissertation, University of British Columbia, July 2008. https://circle.ubc.ca/dspace/handle/2429/2848

Kroeber, Paul (1997). Relativization in Thompson Salish. Anthropological Linguistics 39(3), 376-422.

(1999). The Salish Language Family: Reconstructing Syntax. Lincoln: University of Nebraska Press.

Ladd, D. Robert (1996). Intonational Phonology. Cambridge: Cambridge UP.

Legate, Julie Ann (2003). Some interface properties of the phase. Linguistic Inquiry 34, 506516.

Lindström, Eva, and Bert Remijsen (2005). Aspects of the prosody of Kuot, a language where intonation ignores stress. Linguistics 43(4), 839-870.

Nespor, Marina, and Wendy Sandler (1999). Prosody in Israeli Sign Language. Language and Speech 42, 143-176.

, and Irene Vogel. 1986. Prosodic Phonology. Dordrecht: Foris.

Rialland, Annie, and Stéphane Robert (2001). The intonational system of Wolof. Linguistics 39(5), 893-939.

Schafer, A.J., and Sun-Ah Jun (2002). Effects of accentual phrasing on adjective interpretation in Korean. In M. Nakayama (ed.) East Asian Language Processing. Stanford: CSLI. 223-255.

Selkirk, Elizabeth. 1995. Sentence prosody: Intonation, stress and phrasing. In J. Goldsmith, ed. The Handbook of Phonological Theory. Cambridge, MA: Blackwell. 550-569.

- and Angelika Kratzer (2007). Phase theory and prosodic spellout: The case of verbs. The Linguistic Review 24(2-3), 93-135.

Shaw, Patricia (2002). On the edge: obstruent clusters in Salish. In L. Bar-el, L. Watt, and I. Wilson, eds. Proceedings of WSCLA 7. Vanvouver: UBCWPL 10. 119-136. 
Thompson, Laurence C., and M. Terry Thompson (1992). The Thompson Language. Missoula: University of Montana Occasional Papers in Linguistics 8.

(1996). Thompson River Salish Dictionary. Missoula: University of Montana Occasional Papers in Linguistics 12.

Truckenbrodt, Hubert (1995). Phonological phrases: their relation to syntax, focus and prominence. Ph.D. dissertation. MIT.

(1999). On the relation between syntactic phrases and phonological phrases. Linguistic Inquiry 30, 219-255.

Vatikiotis-Bateson, Eric (1988). Linguistic Structure and Articulatory Dynamics. Ph.D. Dissertation. Bloomington, IN: Indiana University Linguistics Club.

Vatikiotis-Bateson, Eric, and J. A. S. Kelso (1993). Rhythm type and articulatory dynamics in English, French, and Japanese. Journal of Phonetics 21. 231-265.

Yehia, Hani C., Takaaki Kuratate, and Eric Vatikiotis-Bateson (2002). Linking facial animation, head motion and speech acoustics. Journal of Phonetics 30(3), 555-568.

\section{Appendix}

Data are presented in the orthography developed in Thompson and Thompson $(1992,1996)$. Acute accent ' indicates word-level stress. Symbols not listed are the standard IPA forms. Surface realization of vowels varies depending on context (see Thompson and Thompson 1992).

$$
\begin{array}{ll}
c=[\mathrm{t}]] & s=[\mathrm{d}] \\
\mathrm{c}=[\mathrm{ts}] & \mathrm{s}=[\mathrm{s}] \\
\grave{\mathrm{c}}=\left[\mathrm{ts}^{\prime}\right] & \mathrm{x}=[\chi] \\
e=[\mathfrak{x}, \mathrm{a}, \partial, \varepsilon, \mathrm{e}] & y=[\mathrm{i}, \mathrm{j}] \\
\stackrel{\mathrm{\rho}}{e}=[\wedge] &
\end{array}
$$

Abbreviations in the glosses are based on Thompson and Thompson 1992, 1996, Kroeber 1997:

'-' = affix LINK $=$ predicate modification

$'='=$ clitic LOC $=$ locative $\mathrm{COMP}=$ complementizer $\mathrm{NOM}=$ nominalizer

$\mathrm{CNCL}=$ conjunctive subject clitic $\mathrm{O}, \mathrm{OBJ}=$ object DEM $=$ demonstrative $\mathrm{PL}=$ plural DET $=$ determiner POSS $=$ possessive (affix)

$\mathrm{EMPH}=$ emphatic (independent pronoun) $\mathrm{POCL}=$ possessive subject clitic

EVID $=$ evidential

FUT $=$ future

$\mathrm{IMPF}=$ imperfective

$\mathrm{INCL}=$ indicative subject clitic

INTRANS $=$ intransitive
$\mathrm{S}, \mathrm{SUBJ}=$ subject

$\mathrm{SG}=$ singular

SUBJ.GAP $=$ subject gap suffix

TRANS, $\mathrm{TR}=$ transitivizer 